\title{
Angebot zum Erfahrungsaustausch
}

Für Anregungen, Schilderungen ähnlich gelagerter Fälle oder Mitteilung Ihrer Erfahrungen erreichen Sie mich unter:

www.mediation-coaching-hannover.de

oder

kontakt@coaching-per-mediation.de

und

kontakt@orchester-mediation.de

Mein herzlicher Dank gilt allen, die dieses Essential ermöglicht haben.

Angelika Kutz

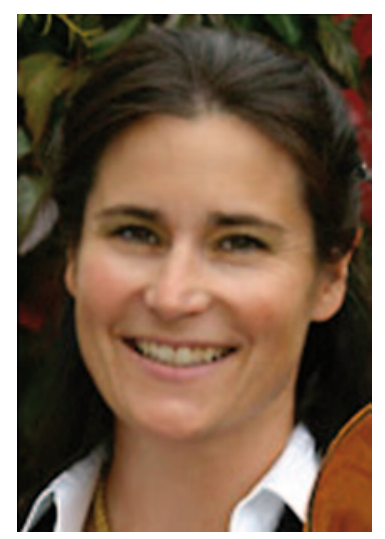

(Foto: Corinna Perrevoort) 